\title{
Ceramic Lined Pipes Produced by a Centrifugal-Thermit Process*
}

\author{
By Osamu Odawara**
}

\begin{abstract}
A new technique is proposed for the ceramic lining of a pipe inner surface by means of a thermit reaction under the influence of a centrifugal force ("Centrifugal-Thermit Process"). The technique is characterized by a large amount of the reaction heat and the centrifugal force applied to the reaction products. In the present work, the effect of the centrifugal force and the characteristics of the thermit reaction in the process are investigated to assess its potential and limitation.

With the increase of the centrifugal force, the compressive strength and the apparent porosity of the products were improved. The compression-shear stress and thermal shock resistances were not necessarily improved. The metal and ceramic layers were uniformly partitioned and a dense ceramic layer was obtained under the centrifugal effect of about 200G. However, small cracks were observed in the ceramic layer.

The propagation rate of the thermit reaction was inversely proportional to the thermit powder density. When the technique is applied to a hollow body, the reaction propagated along the inner surface first and into the layer of the reactant subsequently. It is concluded that the Centrifugal-Thermit process proceeds along the inner surface of the hollow body first and then into the layer in the radial direction resulting in the ceramic lining of homogeneous quality.
\end{abstract}

(Received March 14, 1985)

Keywords: centrifugal-thermit process, ceramic, lining, centrifugal force, exothermic reaction, thermit, propagation of reaction

\section{Introduction}

It is a conventional practice for pipes and vessels of metals to be provided with ceramic lining, in order to improve their resistance against corrosion, abrasion and heat.

Several methods have been proposed for the ceramic lining to a hollow body; that is, the inward surface of the hollow body may be either coated with a ceramic material by baking or a plasma gun technique ${ }^{(1)}$ or bound with a ceramic hollow body of somewhat smaller dimensions inserted therein by filling the narrow interstices with a melt of low melting material $^{(2)}$. The former coating method is limited in the thickness of the ceramic lining layer, so that it is not applicable when a ceramic lining of relatively large thickness is

* Based on the papers published in Tohoku-Kogyo-Gijyutsu-Shikensho Hokoku, 11 (1980), 53; J. Japan Inst. Metals, 45 (1981), 316, etc., in Japanese.

* Government Industrial Research Institute in Tohoku, 4-2-1, Nigatake, Sendai 983, Japan. desired. Besides involving complicated fabrication steps, the latter binding method is not reliable in terms of adhesion strength between the ceramic insert and the metal shell. Therefore, the ceramic layer frequently comes off the metal wall after repeated thermal expansion and contraction or by a mechanical shock.

Thus, none of the conventional methods have been satisfactory in providing a metal hollow body with a sufficiently thick ceramic lining without the danger of peeling or exfoliation even by a large heat shock or mechanical shock.

Recently, a new technique has been proposed for the ceramic lining to a hollow body by means of a thermit reaction taking place under the influence of a centrifugal force ("Centrifugal-Thermit Process"; C-T process) $)^{(3)(4)}$. The technique is characterized by the following two effects. (1) A large input of heat produced by the thermit reaction makes the reaction products immediately melt and form composite with the hollow body. (2) Gases and impurities existing in the reaction products are ex- 
cluded by the influence of the centrifugal force. Since the C-T process is a simple and convenient method for forming a relatively thick ceramic lining layer on a pipe inner surface, it is expected to be applied to a large-sized ceramic lining.

In the present work, the influence of thermit reaction and centrifugal force on the $\mathrm{C}-\mathrm{T}$ process is investigated, in order to determine appropriate conditions for producing good ceramic lining. Production tests under various magnitudes of centrifugal force are performed with a thermit mixture of $\mathrm{Fe}_{3} \mathrm{O}_{4}$ and $\mathrm{Al}$ system. The produced ceramic lined pipes are evaluated by measuring mechanical properties through a squeezing test, a compression-shear test, a thermal shock test, etc. The characteristics of the thermit reaction is studied by measuring the propagation patterns of reaction in the pipes with various densities and shapes of thermit powders.

\section{Principle of a C-T Process ${ }^{(5)}$}

The procedure of the $\mathrm{C}-\mathrm{T}$ process comprises the steps of (1) placing a powdery thermit mixture composed of a strongly reducing element and a reducible metal oxide in the hollow space of the metal pipe, (2) rotating the metal pipe around an axis so that the powdery thermit mixture is pressed against the inward surface of the pipe by the centrifugal force to form a layer, (3) igniting the thermit mixture at one point of the layer formed on the inward surface under the centrifugal effect so that a thermit reaction takes place and the reducible metal oxide is reduced to the molten metal while the strongly reducing element is oxidized to the molten oxide and (4) cooling the pipe which has stratified layers of the metal and the ceramic oxide forming the innermost layer.

In a typical thermit reaction, aluminium oxide and iron are produced by the reaction; $3 \mathrm{Fe}_{3} \mathrm{O}_{4}+8 \mathrm{Al}=4 \mathrm{Al}_{2} \mathrm{O}_{3}+9 \mathrm{Fe}+3265 \mathrm{~kJ}$, and the temperature of the system immediately increases to above $3500 \mathrm{~K}$. Therefore, as shown in Fig. 1, by inducing the thermit reaction in a centrifugated pipe, the inner surface of the pipe melts and forms a composite with the reaction products. Since the density of aluminium

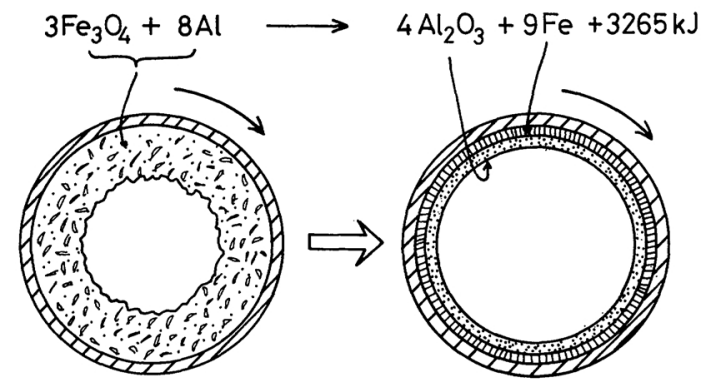

Fig. 1 Principle of a Centrifugal-Thermit Process.

oxide is smaller than that of iron, a thick ceramic layer is formed inward and the product iron is formed in the intermediate region between the pipe and the ceramic layer. With the intermediate metal layer, the produced ceramic lined pipe has not only high strength and toughness of metals and high resistance against corrosion and abrasion of ceramics but also high resistance against thermal and mechanical shocks.

As for thermit mixtures, any combinations of a strongly reducing element and a reducible metal oxide conventionally used in thermit reactions may be used in the $C$ - $T$ process according to the particular need of ceramic lining to be produced. Typical combinations for the CT process are shown in Table $1^{(3)}$, where $T_{\max }$ is the maximum temperature of the system estimated with the data of heat capacity and la-

Table 1 Reaction types and the enthalpies of formation $(\Delta H)$.

\begin{tabular}{|c|c|c|}
\hline Reaction formula & $\begin{array}{c}-\Delta H \\
(\mathrm{~kJ} / \mathrm{mol})\end{array}$ & $T_{\max }(\mathrm{K})^{*}$ \\
\hline $\mathrm{Fe}_{2} \mathrm{O}_{3}+2 \mathrm{Al} \rightarrow \mathrm{Al}_{2} \mathrm{O}_{3}+2 \mathrm{Fe}$ & 836 & 3753 \\
\hline $3 \mathrm{Fe}_{3} \mathrm{O}_{4}+8 \mathrm{Al} \rightarrow 4 \mathrm{Al}_{2} \mathrm{O}_{3}+9 \mathrm{Fe}$ & 816 & 3509 \\
\hline $\mathrm{Cr}_{2} \mathrm{O}_{3}+2 \mathrm{Al} \rightarrow \mathrm{Al}_{2} \mathrm{O}_{3}+2 \mathrm{Cr}$ & 530 & 2460 \\
\hline $3 \mathrm{NiO}+2 \mathrm{Al} \rightarrow \mathrm{Al}_{2} \mathrm{O}_{3}+3 \mathrm{Ni}$ & 928 & 3546 \\
\hline $3 \mathrm{MnO}_{2}+4 \mathrm{Al} \rightarrow 2 \mathrm{Al}_{2} \mathrm{O}_{3}+3 \mathrm{Mn}$ & 878 & 4123 \\
\hline $\mathrm{Fe}_{2} \mathrm{O}_{3}+3 \mathrm{Mg} \rightarrow 3 \mathrm{MgO}+2 \mathrm{Fe}$ & 323 & 3076 \\
\hline $\mathrm{Fe}_{3} \mathrm{O}_{4}+4 \mathrm{Mg} \rightarrow 4 \mathrm{MgO}+3 \mathrm{Fe}$ & 316 & 3148 \\
\hline $\mathrm{Cr}_{2} \mathrm{O}_{3}+3 \mathrm{Mg} \rightarrow 3 \mathrm{MgO}+2 \mathrm{Cr}$ & 221 & 2181 \\
\hline $\mathrm{NiO}+\mathrm{Mg} \rightarrow \mathrm{MgO}+\mathrm{Ni}$ & 353 & 2579 \\
\hline $\mathrm{MnO}_{2}+2 \mathrm{Mg} \rightarrow 2 \mathrm{MgO}+\mathrm{Mn}$ & 337 & 3665 \\
\hline $2 \mathrm{Fe}_{2} \mathrm{O}_{3}+3 \mathrm{Si} \rightarrow 3 \mathrm{SiO}_{2}+4 \mathrm{Fe}$ & 311 & 2626 \\
\hline $\mathrm{Fe}_{3} \mathrm{O}_{4}+2 \mathrm{Si} \rightarrow 2 \mathrm{SiO}_{2}+3 \mathrm{Fe}$ & 298 & $(1808)$ \\
\hline $2 \mathrm{NiO}+\mathrm{Si} \rightarrow \mathrm{SiO}_{2}+2 \mathrm{Ni}$ & 373 & 2602 \\
\hline $\mathrm{MnO}_{2}+\mathrm{Si} \rightarrow \mathrm{SiO}_{2}+\mathrm{Mn}$ & 339 & 3024 \\
\hline
\end{tabular}

* Maximum temperature of the products by the reaction. 
tent heat of the system. The strongly reducing element is selected from the group consisting of aluminium, magnesium and silicon, among which aluminium having an ignition temperature of about $1500 \mathrm{~K}$ is the most preferred owing to the easiness in controlling the thermit reaction. On the other hand, the thermit reaction with magnesium alone as the strongly reducing element is too violent and hence is less preferred while the ignition temperature of the thermit reaction with silicon alone is too high. However, the use of these elements in combination is somewhat advantageous in providing a means for controlling the ignition temperature or in giving a denser structure of the ceramic layer by the effect of decreasing the melting temperature of aluminium oxide.

\section{Experimental Procedures}

\section{Production tests under various magnitudes of centrifugal force}

A thermit mixture was prepared by blending $78 \mathrm{~g}$ of aluminium powder $(\sim 100 \mu \mathrm{m})$ and 250 $\mathrm{g}$ of ferrosoferric oxide $(\sim 5 \mu \mathrm{m})$. A carbon steel pipe (STPG) with an outer diameter of 76 $\mathrm{mm}$ and a wall thickness of $4 \mathrm{~mm}$ cut in a length of $100 \mathrm{~mm}$ was mounted on a centrifuge mechine and loosely filled with the thermit mixture.

After the rotation of the centrifuge machine had reached to a fixed velocity, the thermit mixture was ignited by an acetylene torch. The thermit reaction was completed instantaneously and, after completion of the reaction, the rotation of the centrifuge machine was continued for a while further to cool down the body. The rotation of the centrifuge machine was varied $9,20,27,34$ and $39 \mathrm{~s}^{-1}$, which made the thermit powder receive the centrifugal effect of $11,55,100,158$ and $208 \mathrm{G}$, respectively.

In order to measure the temperature hysteresis of the products in the process, an infrared radiation thermometer (IR-P3C) manufactured by CHINO WORKS, Ltd. was placed on a level with the centrifuge machine at about $3 \mathrm{~m}$ from it and was focused on the inside of the pipe. As a comparison, the temperature hysteresis in a static thermit reaction was also measured in the same manner.

\section{Measurements of the mechanical properties of the products}

The properties of the produced ceramic lined pipe were investigated through a squeezing test, a compression-shear test, a thermal shock test and measurements of hardness and apparent porosity of the product layers.

Schematic illustrations of the squeezing test and the compression-shear test are shown in Fig. 2(A) and (B), respectively. The pipe provided with the ceramic lining layer was cut in a radial plane into a ring-wise piece $10 \mathrm{~mm}$ in width, and this ring-wise test piece was subjected to the squeezing test by compressing in the radial direction as shown in Fig. 2(A). In the compression-shear test, the ring-wise test piece $10 \mathrm{~mm}$ in width was compressed in a

(A)
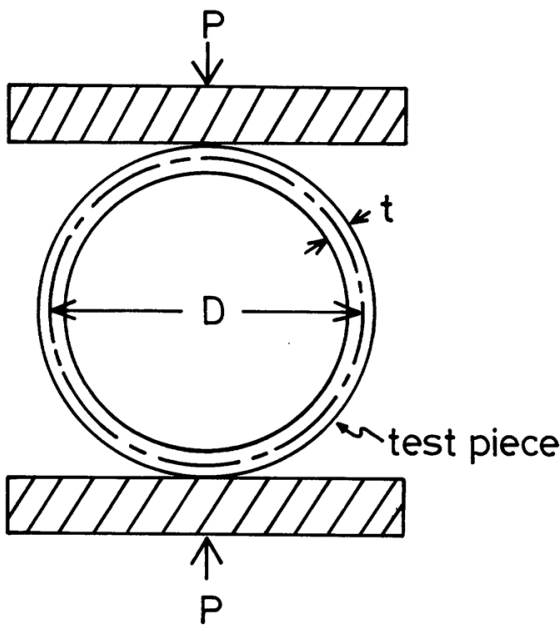

(B)

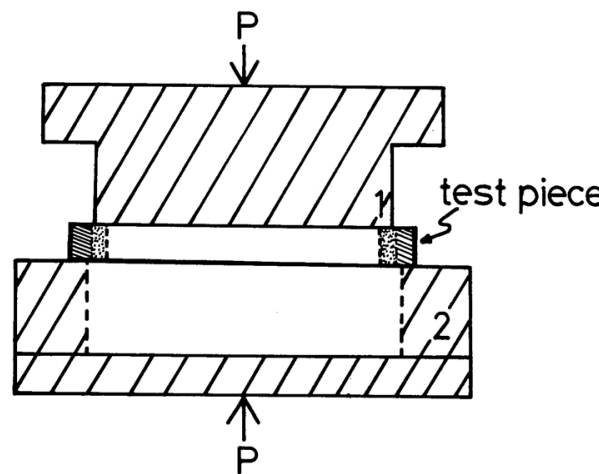

Fig. 2 Schematic illustrations of a squeezing test (A) and a compression-shear test (B). 
radial plane with an upper tool (1) attached to the ceramic layer and a bottom tool (2) attached to the metal layers.

\section{Measurements of reaction propagation patterns in thermit reactions}

Test samples were prepared by filling the thermit powders of $\mathrm{Fe}_{3} \mathrm{O}_{4}-\mathrm{Al}$ system in STPG pipes of the same dimensions as the pipe used in the previous production tests. For the experiments with the fully filled samples, the ratio of the powder density $\left(\rho / \rho_{T}\right)$ was varied from 0.15 to 0.32 , where $\rho_{T}$ was the theoretical density of the powder $\left(4.26 \times 10^{3} \mathrm{~kg} / \mathrm{m}^{3}\right)$. For the experiments with the samples having a hollow part inside, the total amount of the thermit powder was $330 \mathrm{~g}$ in every case and the diameters of the hollow part were 30 and 14 $\mathrm{mm}$. The reaction was started by igniting one end of the sample pipe with electrical heating of Mo wire $(0.5 \mathrm{~mm}$ in diameter). The propagation rate of reaction was evaluated by measuring the time delay of the temperature increase from the ignition at fixed points of thermocouples.

\section{Results and Discussion}

\section{Temperature hysteresis in a $\mathbf{C}-\mathbf{T}$ process}

Since the present measurement of temperature with an infrared radiation thermometer is carried out through the radiation on the surface of materials, the information is much influenced by the quality and conditions of the surface of the measured material. Therefore, for estimating the true temperature in a $\mathrm{C}-\mathrm{T}$ process by this method, it is essential to obtain an exact emissivity of the produced ceramic layer. In the present $\mathrm{C}-\mathrm{T}$ process which is quite complex in the reaction and includes the processes of melting and solidification around $2300 \mathrm{~K}$, it is difficult to obtain accurate emissivity of the ceramic product. Thus, a piece of the ceramic was put in an electric furnace and the emissivity was checked up to $1773 \mathrm{~K}$ by both thermocouples and the infrared radiation thermometer, in order to compare the temperature values obtained from the two instruments. Through this comparison the emissivity of the

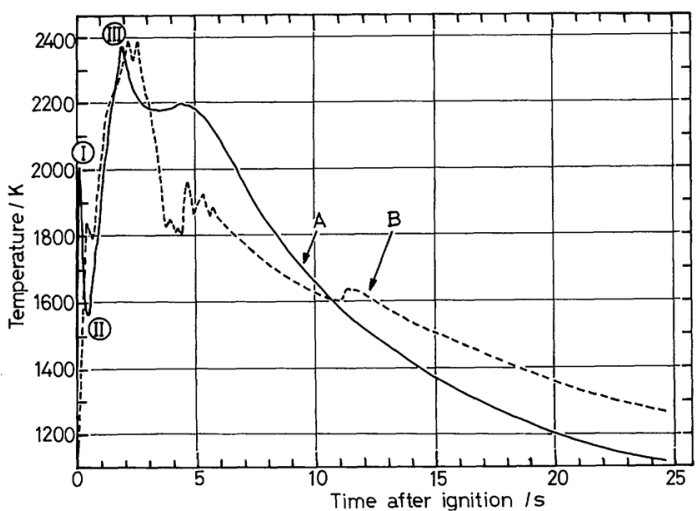

Fig. 3 Temperature changes in a C-T process (A) and a static thermit reaction (B).

(I): blowup point. (I)-(II): blowoff of fumes. (III-(III): completion of reaction.

present ceramic was estimated to be 1.0 . Then, the measurement was carried out at the emissivity of 1.0 in the present experiments.

In Fig. 3, the results of the measurements in the $C$ - $T$ process under the rotation of $39 \mathrm{~s}^{-1}$ and in a static thermit reaction are shown by a solid line and a dashed line, respectively. As shown in Fig. 3, the temperature acutely rose with the start of reaction and dropped rapidly in the fumy condition after the blowup (0.1$0.5 \mathrm{~s}$ in the C-T process) following the inducement of reaction at the whole part. Subsequently, the highest temperature was reached after about $2 \mathrm{~s}$ from the ignition and was followed by the cooling process. Since the reaction products were melted by the reaction heat, it is assumed that the emissivity would change drastically at the melting point of the products. Therefore, the true peak would be much higher than $2400 \mathrm{~K}$ which was the highest one in Fig. 3 . In the cooling stage, a plateau appeared at about $2200 \mathrm{~K}$ which was considered to be the melting point of the ceramic product. The time interval of the plateau in the C-T process was longer than that in the static thermit reaction. In this reaction, an anomalous increase appeared at about $1700 \mathrm{~K}$, which was considered to be the melting point of the iron product. No anomaly was observed at that point in the C-T process, because the iron layer did not exist in the inner surface owing to the effect of the centrifugal force. In the cooling process, the gradient of temperature curve in the $\mathrm{C}-\mathrm{T}$ process 
was steeper than that in the static thermit reaction.

As a result, it is considered that the cooling in the C-T process occurs in the radial direction predominantly, so that the created heat was kept inside of the pipe in the reaction process and, once the heat is conducted to the metal mold, the system would be cooled down acceleratedly by the effect of the centrifugal force. As shown in Fig. 3, the reaction process proceeds very quickly within $2 \mathrm{~s}$, but the time interval in which temperature stays at more than the melting point of the products is more than $4 \mathrm{~s}$. Therefore, it may be possible to control the quality of the products in some way in this stage.

\section{Effect of the centrifugal force on the formation of layers}

The partial cross sections of the pipes obtained under $11,55,100$ and $208 \mathrm{G}$ are shown in Fig. 4(A), (B), (C) and (D), respectively. As shown in Fig. 4(A), the partition of the ceramic and metal was not completed under $11 \mathrm{G}$, and a part of the product metal appeared on the inner surface. Under 55G, the partition was almost completed, and the product metal was distributed in the intermediate part of the pipe, although the layers of the products were not uniformly formed. The formation of layers was improved with the increase of the centrifugal force, and the entanglement of the ceramic behind the product metal was much decreased under $100 \mathrm{G}$. When the centrifugal force reached $208 \mathrm{G}$, the layers of ceramic and metal were uniformly formed, and the boundary between the ceramic and the metal was also clear. The ceramic layer produced under $208 \mathrm{G}$ was considerably dense $(\sim 7 \%$ in the apparent porosity), although some small cracks were observed in it.

\section{Effect of the centrifugal force on the properties of the pipe}

In the present squeezing test, the strength of the pipe has been evaluated by compressing a ring-wise test piece in a radial direction, where the uniformity and completion of the product layers in the partition would affect the obtained results predominantly. Load-deformation curves obtained by the squeezing test for the pipes produced under various magnitudes of
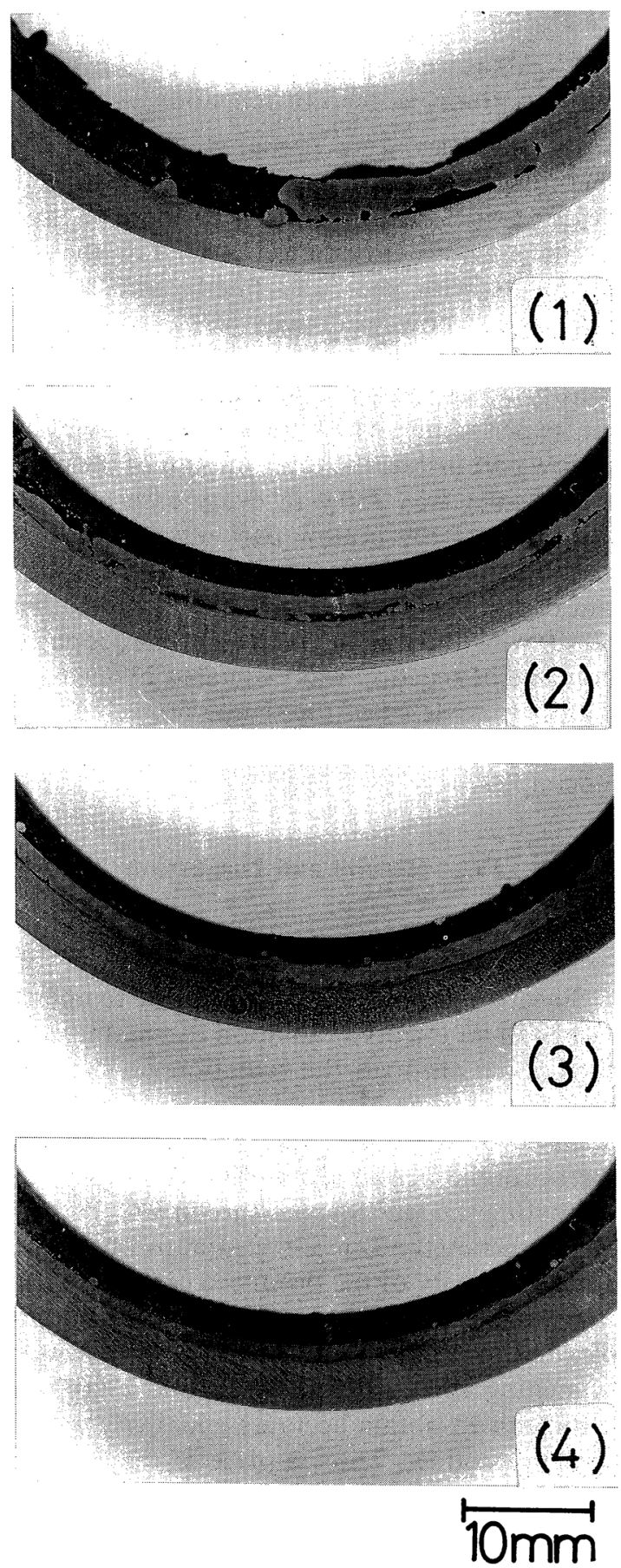

Fig. 4 Cross section of the pipes produced under various magnitudes of centrigugal force.

(1): under 11G. (2): under 55G. (3): under 100G.

(4): under $208 \mathrm{G}$. 


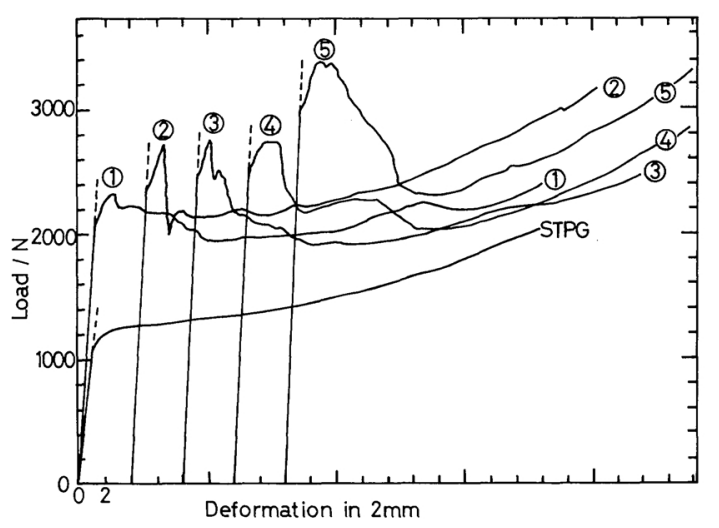

Fig. 5 Load-deformation curves of the present pipes obtained by a squeezing test.

(1): under 11G. (2): under 55G. (3): under 100G. (4): under 158G. (5): under 208G.

centrifugal force are shown in Fig. 5. As a comparison, the result for the metal pipe used as the outer pipe (STPG) is also shown in the figure. As shown in Fig. 5, the deformation ratio within the proportional limit was not so different in each case (2-3\%), and the breaking load, that is, the load causing the ceramic layer to be destroyed increased with the increase of the centrifugal force. The breaking load shows little difference in the pipes produced under 55 to $158 \mathrm{G}$, but the value is remarkably high in the test sample produced under $208 \mathrm{G}$.

From eq. (1), the strength of the pipe in a horizontal-radial direction $\left(\sigma_{p}\right)$ was estimated at the proportional limit $(P)$.

$$
\sigma_{p}=P / \pi L t \times[1+\{t /(D+t)\} / K] /(1+K),
$$

where $L, t$ and $D$ are the width, thickness and average diameter of test pieces, respectively. $K$ is a cross section factor given as $-1+D / 2 t \times 1 \mathrm{n}$ $\{(D+t) /(D-t)\}$. Calculated results in the present work are shown in Table 2. Table 2 also shows the average thickness of the product layers $\left(t_{p}\right)$, average density of the products $\left(\rho_{p a}\right)$, apparent porosity of the products $\left(P_{p}\right)$, Vickers hardness of the product ceramic $(\mathrm{Hv})$ and the compression-shear stress $\left(\sigma_{s}\right)$. The compression-shear stress was estimated from eq. (2) by measuring the maximum load $\left(P_{m}\right)$, when the ceramic layer was exfoliated from the metal layer, and the diameter of the pipe after the exfoliation $\left(D_{\text {in }}\right)$.

$$
\sigma_{s}=P_{m} /\left(\pi L D_{i n}\right)
$$

As shown in Table 2, the hardness of the product ceramic was more than 10 times as large as that of the STPG pipe and almost independent of the effect of the centrifugal force. On the other hand, the apparent porosity of the products and the strength evaluated by the squeezing test correlated with the centrifugal force. These properties improved with the increase of the centrifugal force, although there were slight differences between the pipes obtained under 55, 100 and 158G. The strength of the pipe produced under $208 \mathrm{G}$ was slightly less than that of the STPG pipe; therefore, it is considered that the present ceramic lined pipe would possess the compressive strength as high as that of the outer metal pipe. In terms of the compression-shear stress, the centrifugal force was effectively applied to the pipes produced under up to $158 \mathrm{G}$.

The results of thermal shock test are shown in Table 3. Within the present experimental precision, it was considered that none of the test samples were damaged up to $773 \mathrm{~K}$. The sample obtained under $11 \mathrm{G}$ was attacked by thermal shock causing some small cracks on the ceramic layer at $973 \mathrm{~K}$ and was partly destroyed at more than $1373 \mathrm{~K}$. The other samples were attacked at $1173 \mathrm{~K}$ except the one

Table 2 Experimental data on the mechanical properties obtained in the present work.

\begin{tabular}{cccccccc}
\hline $\begin{array}{c}\text { Expt1. } \\
\text { No. }\end{array}$ & $\begin{array}{c}\text { G. } \\
\text { No. }\end{array}$ & $\begin{array}{c}t_{p} \\
(\mathrm{~mm})\end{array}$ & $\begin{array}{c}\rho_{p a} \\
\left(\mathrm{~kg} / \mathrm{m}^{3}\right)\end{array}$ & $\begin{array}{c}P_{p} \\
(\%)\end{array}$ & $\begin{array}{c}\text { Hardness } \\
(\mathrm{Hv})\end{array}$ & $\begin{array}{c}\sigma_{p} \\
(\mathrm{MPa})\end{array}$ & $\begin{array}{c}\sigma_{s} \\
(\mathrm{MPa})\end{array}$ \\
\hline 1 & 11 & 4.40 & $3.64 \times 10^{3}$ & 33.2 & $1513 \pm 48$ & 210 & - \\
2 & 55 & 4.25 & $4.38 \times 10^{3}$ & 19.7 & $1514 \pm 118$ & 250 & 6.4 \\
3 & 100 & 4.10 & $4.32 \times 10^{3}$ & 20.8 & $1534 \pm 104$ & 264 & 17.1 \\
4 & 158 & 3.90 & $4.39 \times 10^{3}$ & 19.5 & $1630 \pm 174$ & 279 & 21.2 \\
5 & 208 & 3.85 & $4.80 \times 10^{3}$ & 12.0 & $1608 \pm 312$ & 343 & 20.0 \\
STPG & - & - & - & - & $145 \pm 2$ & 400 & - \\
\hline \hline
\end{tabular}


Table 3 Thermal shock data obtained in the present work.

\begin{tabular}{ccccccc}
\hline & & \multicolumn{5}{c}{ Temperature (K) } \\
\cline { 3 - 7 } Exptl.No. & G. No. & 573 & 773 & 973 & 1173 & 1373 \\
\hline 1 & 11 & A & A & B & B & C \\
2 & 55 & A & A & A & B & B \\
3 & 100 & A & A & A & A & B \\
4 & 158 & A & A & A & B & B \\
5 & 208 & A & A & A & B & B \\
\hline \hline
\end{tabular}

A: non-attack by the thermal shock, B: small cracks observed, C: partly destroyed in the ceramic layer.

produced under $100 \mathrm{G}$. Thus, it was confirmed that the ceramic lined pipes produced by more than $55 \mathrm{G}$ would be possible to be utilized at least up to $973 \mathrm{~K}$, and the increase of the centrifugal force is not necessarily effective to the thermal shock resistance of the product pipe, although it has not been done in the present work to confirm the growth of small cracks followed by the destruction of the ceramic layer at higher temperatures.

Therefore, the effect of the centrifugal force is considered to be evident in producing uniform layers and enhancing properties of materials such as the porosity and the strength in the squeezing test. However, the excessive centrifugal force would decrease the binding force between layers and deteriorate the internal uniformity of the ceramic, and it would give no advantage to properties such as compression-shear stress and thermal shock resistance.

\section{Characteristics of thermit reactions in a C-T process}

Researches on a $\mathrm{C}$ - $\mathrm{T}$ process have been recently extended to the development of $6 \mathrm{~m}$ class long ceramic lined pipes. In the process of the development, it has been confirmed that the thermit reaction proceeds rapidly to produce the ceramic lining of homogeneous quality in the direction of pipe length by igniting only a part of reactant under the conditions of proper amount of thermit powders and proper centrifugal force ${ }^{(6)}$. Considering this fact from the fundamental point of view, important research subject would be included in the production of homogeneous ceramic lining
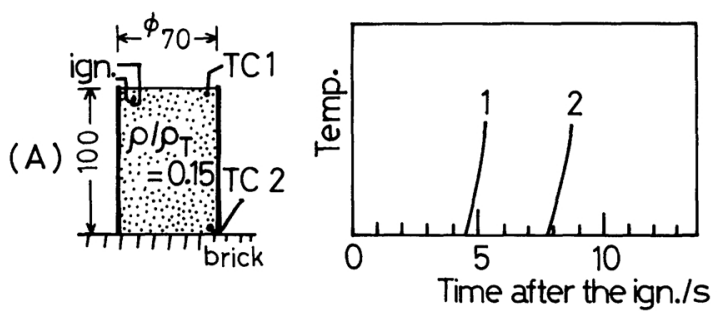

(B)
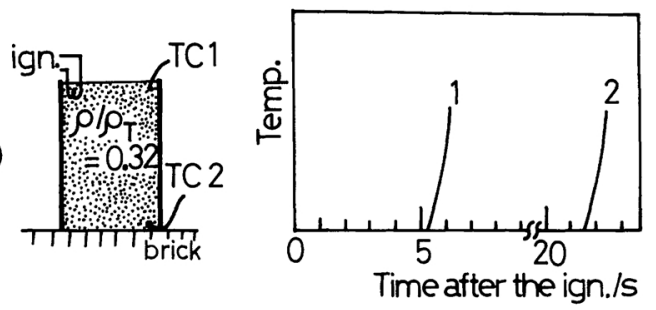

(C)
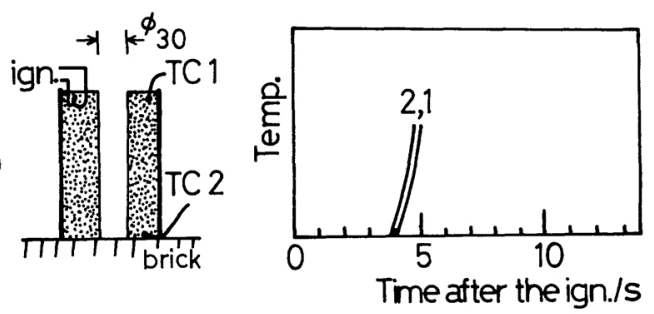

Fig. 6 Typical propagation patterns of the present thermit reactions (1).

through the rapid progress of reaction in the C-T process with a partial ignition.

In the present reaction system of ferrosoferric oxide and aluminium powders, the temperature of the reacting system is considered to reach above $3500 \mathrm{~K}$. Therefore, since the boiling points of $\mathrm{Al}$ and $\mathrm{Fe}_{3} \mathrm{O}_{4}$ are considered to be less than $3000 \mathrm{~K}^{(7)}$, the present thermit reaction would mainly proceed in a reaction of gas phase. Moreover, if the temperature of the system exceeds the boiling points of the products which are above $3200 \mathrm{~K}$, the reactant and the products would form a gas phase, and the system would include the dispersion or accelerated diffusion of the reactant, even if the thermit reaction does not form any gaseous reaction products ${ }^{(8)}$.

In Fig. 6, typical results of time delays in temperature increase measured by thermocouples at fixed points are shown with various thermit powder densities and shapes. The measurements have been done by recording the 
temperature increase with two thermocouples placed on the top end (TC1) and the bottom end (TC2) of the sample pipe. As the thermocouples have been melted by the reaction heat, the curves of the temperature rise are imaginary ones based on our best estimation.

As can be seen from Fig. 6(A) and (B), the time interval between the change in TC1 and that in TC2 in the reaction with the density ratio of 0.32 is longer than that of 0.15 . This result would be comprehensible, if considering high temperature gas diffusion as a predominant factor in the present reaction, that is, the diffusion of gas is hindered with the increase of the powder density, because the free space becomes smaller and the propagation of reaction becomes slower even the conduction of heat becomes better with the increase of the density. On the other hand, when reacting in the sample pipe with a hollow body $30 \mathrm{~mm}$ in diameter (see Fig. 6(C)), the temperature increase of TC1 and TC2 occurs almost at the same time. It is also considered that the reaction proceeds along the inner surface of the hollow body firstly.

The relationship between the powder density and the propagation rate of reaction is shown in Fig. 7. Although a lot of researches have been done on the combustion of condensed matters $^{(9)-(13)}$, only a few systematic works have been reported because of the complication of the phenomena. According to Merzhanov $^{(9)}$

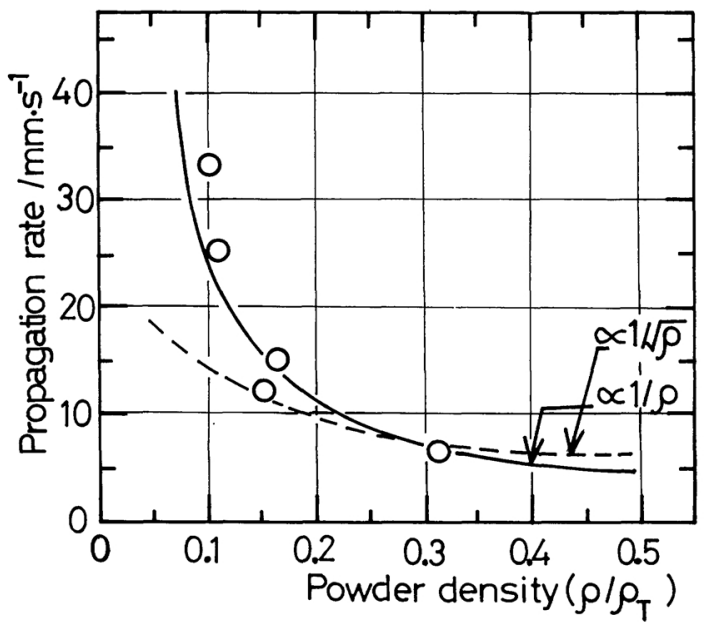

Fig. 7 Relationship between propagation rate of reaction and thermit powder density. $\bigcirc$ : present result. who has theoretically investigated the combustion of condensed matters in consideration of the simplest one-stage combustion and the separated process of combustion zone from others, the propagation rate of combustion has been proportionally related with the inverse of square root of the reactant density in a gasless reaction and with the inverse of the reactant density in the case of the combustion proceeding in gas phase. Since the present results are inversely proportional to the powder density as can be seen from Fig. 7, it would be possible to consider that the present thermit reaction is predominantly affected by a gas phase reaction followed by the dispersion or dissociation of the matter.

The characteristics of reaction in the sample with a hollow part has been tested much in details by putting the sample pipe horizontally and measuring the temperature further in a hollow part (TC3). The typical results are shown in Fig. 8, in which the thermocouples of TC1 and TC2 were inserted in the thermit powder about $10 \mathrm{~mm}$ deep and the distance between TC1 and TC2 was $50 \mathrm{~mm}$. In the structure shown in Fig. 8(A), the temperature at TC 3 increased first, and that at TC 1 increased subsequently. The temperature increase at TC2 was the last, and the time intervals from that of TC 3 and that of TC1 were about 3.4 and $1.8 \mathrm{~s}$, respectively. Since the distance

(A)

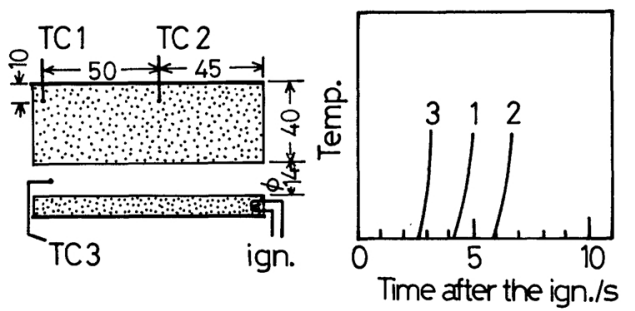

(B)
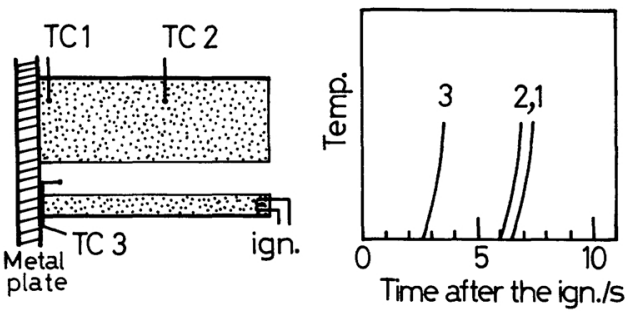

Fig. 8 Typical propagation patterns of the present thermit reactions (2). 
between the thermocouple put in the sample powder and the surface of the hollow part was about $30 \mathrm{~mm}$, the temperature increase at the thermocouple would be delayed by about $2.7 \mathrm{~s}$ from that on the inner surface, if the reaction proceeds in the powder layer $30 \mathrm{~mm}$ in the radial direction with the propagation rate estimated from Fig. 7. Therefore, the characteristics of TC2 can be explained, if it is assumed that the reaction process proceeds in the hollow part first and subsequently in the radial direction. However, the temperature at TC 1 increased much earlier, and from this fact it is assumed that the end of the pipe has something to do with the TC1 characteristics. Then, the effect of the end was covered with a metal plate as shown in Fig. 8(B). The result was that the temperature increase at TC1 was almost at the same time as at TC2.

As a result of the present experiments, it is confirmed that the reaction propagates on the inner surface first and afterward into the layer of reactant when it has a hollow body. Therefore, it is considered that the $\mathrm{C}-\mathrm{T}$ process would also make the reaction proceed on the inner surface of hollow body first and then into the layer in the radial direction simultaneously, which would make the production of long-sized ceramic lined pipes of homogeneous quality possible.

\section{Conclusion}

In order to confirm the potential and limitation of the "Centrifugal-Thermit Process" for the ceramic lining of a pipe, the characteristics of thermit reactions and the effect of the centrifugal force were investigated in the present work. The results are summarized as follows:

(1) With the increase of the centrifugal force, the properties of the product pipe are improved in both compressive strength and porosity of the product layers. However, compression-shear stress and thermal shock resistance are not necessarily improved, when the pipes are produced under some excessive centrifugal force. The main effect of the centrifugal force is considered to be in the formation of the uniform product layers. The optimum effect is considered to be in the region from 55 to $208 \mathrm{G}$ in the present work.

(2) Although the mechanism of thermit reactions is too complex and difficult to make clear in details, the mechanism of the propagation of reaction in the $\mathrm{C}$ - $\mathrm{T}$ process was qualitatively confirmed through the experiments on the thermit reactions with various densities and shapes of thermit mixtures. The reaction proceeds in a hollow surface first and subsequently in the radial direction simultaneously. The produced ceramic lined pipes have a homogeneous quality in the direction of the pipe length. Although it is important to investigate much in details the effects of additives in the reactant, pre-heating of the system, etc. for improving the quality of the ceramic lined pipe itself, the present consideration would become one of the advantageous guiding principles on the way to such improvements.

\section{REFERENCES}

(1) M. Seki and k. Ishikawa: J. JSME, 82 (1979), 58.

(2) Y. Komatsu: Bull. Japan Inst. Metals, 18 (1979), 48 (in Japanese).

(3) O. Odawara: Tohoku Kogyo-Gijyutsu-Shikensho Hokoku, 11 (1980), 53.

(4) O. Odawara and J. Ikeuchi: J. Japan Inst. Metals, 45 (1981), 316 (in Japanese).

(5) O. Odawara: U. S. Patent No. 4363832 (1982); Japan Patent No. 1144098 (1983).

(6) O. Odawara, M. Shiraishi, J. Ikeuchi, H. Yamasaki, M. Sato and Y. Ishii: to be published in J. Japan Inst. Metals.

(7) O. Kubaschewski and C. B. Alcock: Metalurgical Thermochemistry, Pergamon Press, U. K. (1979), p. 358.

(8) E. I. Maksimov, A. G. Merzhanov and V. M. Shkiro: Fiz. Goreniya i Vzryva, 1 (4) (1965), 24.

(9) A. G. Merzhanov: Combustion and Flame, 13 (1969), 143.

(10) B. I. Khaikin and A. G. Merzhanov: Fiz. Goreniya i Vzryva, 2 (3) (1966), 36.

(11) A. G. Merzhanov: Combustion and Flame, 11 (1967), 201.

(12) D. K. Kuehl: AIAA paper, No. 65-103 (1965).

(13) E. I. Maksimov and A. G. Merzhanov: Fiz. Goreniya i Vzryva, 2 (1) (1966), 47. 